\title{
Protective Effects of Pinus halepensis Bark Extract and Nicotine on Cigarette Smoke-induced Oxidative Stress in Keratinocytes
}

\author{
PANAGOULA PAVLOU ${ }^{1}$, IOANNA ANTONIADOU ${ }^{1}$, ASIMINA PERAKI ${ }^{1}$, ANDREAS VITSOS ${ }^{1}$, \\ PARASKEVAS DALLAS ${ }^{1}$, DIMITRIOS MOSTRATOS ${ }^{1}$, GEORGIOS DELICONSTANTINOS ${ }^{2 \dagger}$, \\ GEORGIOS PAPAIOANNOU ${ }^{1}$, SERGEI A. GRANDO ${ }^{3}$ and MICHAIL RALLIS ${ }^{1}$ \\ ${ }^{1}$ National and Kapodistrian University of Athens, School of Health Sciences, \\ Department of Pharmacy, Athens, Greece; \\ ${ }^{2}$ National and Kapodistrian University of Athens, School of Medicine, \\ Department of Experimental Physiology, Athens, Greece; \\ ${ }^{3}$ University of California, Health Gottschalk Medical Plaza, Institute for Immunology, Irvine, CA, U.S.A.
}

\begin{abstract}
Background/Aim: Cigarette smoke (CS) is a major environmental health threat. The oxidative stress induced by CS on keratinocytes and the possible protective effect of nicotine, its receptor inhibitors, and Pinus halepensis bark extract in relation to known antioxidants were investigated. Materials and Methods: Primary mouse keratinocytes were exposed to cigarette smoke in the presence and absence of Pinus halepensis bark extract $(1 \mu \mathrm{g} / \mathrm{ml})$, rutin $(50 \mu \mathrm{M})$ and ascorbic acid $(250 \mu M)$, nicotine $(1 \mu M)$ with or without mecamylamine $(5 \mu M)$ and $\alpha$-bungarotoxin $(0.1 \mu M)$. Keratinocyte viability and oxidative stress were evaluated by MTT and fluorescence assays. Results: Pinus halepensis bark extract decreased the oxidative stress and increased the viability of keratinocytes, and moreover, these effects were more pronounced compared to the mixture of rutin and $L$ ascorbic acid. Nicotine significantly enhanced the viability potentiation of the beneficial effect induced by Pinus halepensis bark extract. Mecamylamine and $\alpha$-bungarotoxin showed no specific effect. Conclusion: Pinus halepensis bark extract in combination with nicotine may successfully reverse skin damage induced by cigarette smoke.
\end{abstract}

This article is freely accessible online.

$\dagger$ This manuscript is dedicated to our beloved Professor Georgios Deliconstantinos, who passed away recently.

Correspondence to: Michail Rallis, Ph.D., National and Kapodistrian University of Athens, School of Health Sciences, Department of Pharmacy, Division of Pharmaceutical Technology, Panepistimiopolis, 15784 Athens, Greece. Tel: +30 2107274699, +30 6975505955, Fax: +30 2107274027, e-mail: rallis@pharm.uoa.gr

Key Words: Oxidative stress, cigarette smoke, keratinocytes, Pinus halepensis bark extract, nicotine.
Cigarette smoke (CS) is a global problem of our society and according to the World Health Organization "the tobacco epidemic is one of the biggest public health threats the world has ever faced, killing more than 8 million people a year" (1). The Lancet Commission on pollution and health characterized $\mathrm{CS}$ as more dangerous than AIDS, tuberculosis, and malaria (2). CS is associated with cardiovascular diseases, higher risk of skin diseases, such as squamous cell carcinoma and atopic dermatitis, and is connected with decreased wound healing rate (3-7). The skin is the most important target for the harmful effect of CS pollution. Both solid and gas products of CS contain aniline, $N$-nitrosodimethylamine, benzopyrenes, acrolein, formaldehyde, $N$-nitrosopyrrolidine that are considered to be toxic, causing serious oxidative damage (8). CS produces reactive oxygen and nitrogen species oxidizing important biomolecules such as DNA, proteins and lipids leading to tissue injury which is translated to enhanced inflammatory phenomena (9-14).

One of the main constituents of CS is nicotine; it is an agonist of acetylcholine and acts on the epidermis via the keratinocyte nicotinic acetylcholine receptors (nAChRs) (15). nAChRs are large $(290 \mathrm{kDa})$ pentameric transmembrane complexes, which are ligand-gated ion channels (LGICs) permeable to $\mathrm{Na}, \mathrm{K}$ and $\mathrm{Ca}$ ions $(16,17)$. Nicotine activity is doubtful as it has been shown to exert both toxic and beneficial effects; it has been reported as neurotoxic and neuroprotectant (18), toxic to muscles and lung epithelium $(19,20)$, beneficial in colitis $(21)$, while its potential activity on mitochondria apparently requires further investigation (22). Concerning inflammatory and wound healing processes, the effect of nicotine is considered rather negative, while topical $n A c h R$ antagonists have been shown to improve these negative effects $(18,23,24)$. Topically applied antioxidants like L-ascorbic acid and a-tocopherol, as well as rutin, correctly formulated, seem to protect skin against environmentally induced oxidative damage $(25,26)$. 
On the other hand, there are many published studies, where the researchers evaluate the antioxidant activity of extracts of various plant extracts. Among them, Pinus halepensis, also known as Aleppo pine, is a Mediterranean pine with a bark extract rich in phenolic antioxidants, such as procyanidins and phenolic acids, which appears to effectively protect against skin inflammation induced by Xrays and UV radiation, in vivo $(27,28)$. Moreover, Pinus maritima bark extract has been shown to protect skin against tobacco smoke and UV radiation (29-31).

The present study aimed to evaluate the antioxidant effect of Pinus halepensis bark extract in comparison to the known synthesized antioxidants, such as rutin and ascorbic acid, on the CS-induced oxidative damage on keratinocytes. In addition, the role of nicotine and its receptor antagonists, $\alpha$ bungarotoxin and mecamylamine, in the CS-induced oxidative stress was also investigated. Since epidermal cells come into direct exposure with CS, it would be of great interest to examine possible mechanisms to prevent the induced damage.

\section{Materials and Methods}

Chemicals. The chemicals nicotine, hydrochloride mecamylamine, $\alpha$-bungarotoxin (toxin, snake from Bungarus multicinctus), rutin hydrate and L-ascorbic acid (sodium salt), Dulbecco's phosphate buffered saline (DPBS) were purchased from Sigma-Aldrich (Darmstadt, Germany). All compounds were of analytical grade. Cetavlon (Cetrimide 20\% w/v) was obtained from Cana Laboratories S.A. (Athens, Greece), accutase containing $0.5 \mathrm{mM}$ EDTA from Chemicon International (Temecula, CA, USA), and 3(4,5-Dimethylthiazol-2-yl)-2,5-diphenyltetrazolium bromide (MTT) from Sigma-Aldrich (St Louis, MO, USA). The dispase (1.12 units/mg), the keratinocyte serum-free medium (SFM), bovine pituitary extract, recombinant epidermal growth factor (rEGF) and 6-chloromethyl-2',7'-dichlorodihydrofluorescein diacetate, acetyl ester (CM-H2DCFDA) were purchased from Gibco-Life Technologies (ThermoFisher Scientific, USA).

CS environment. The cigarette smoking environment was simulated by using the smoking apparatus from CH8152, type MCF (Ismatec SA, Glattbrugg, Switzerland). The oxidative stress was measured by using a Fluostar Galaxy spectrometer, fluorescence and chemiluminescence meter, BMG Labtech, Germany.

Pinus halepensis bark extract preparation. Pinus halepensis bark was collected from Kaisariani forest (Athens, Greece) and extracted as previously described (27). In brief the bark was powdered, extracted with distilled water, freeze dried and dissolved in keratinocyte SFM $(1 \mu \mathrm{g} / \mathrm{ml})$.

Cell isolation and culture. Primary keratinocytes were obtained from neonatal ( $\leq 24 \mathrm{~h}$ old) SKH-HR1 and SKH-HR2 mice. Briefly, the excised skin was immersed in isopropanol $70 \%$ solution, rinsed with PBS, and dipped into PBS solution containing gentamycin ( $7 \mu \mathrm{g} / \mathrm{ml}$; Schering-Plough Ltd, New Jersey, USA). Subcutaneous adipose tissue and skin main vessels were carefully removed and skin was immersed in a Petri dish containing dispase-PBS $(0.2$ $\mathrm{U} / \mathrm{ml})$. Skin was cut in small pieces and incubated under stirring $(250 \mathrm{rpm}$ ) for at least $1 \mathrm{~h}$; then, the mixture was centrifuged at 1000 $\mathrm{rpm}$, the dispase solution was discarded and the remaining cells were grown in keratinocyte SFM with low calcium chloride concentration $(0.045 \mathrm{mM})$, containing $20-30 \mu \mathrm{g} / \mathrm{ml}$ bovine pituitary extract, and $0.1-0.2 \mathrm{ng} / \mathrm{ml} \mathrm{rEGF}$. Cells were maintained in a humidified atmosphere of $5 \% \mathrm{CO}_{2}$, at $37^{\circ} \mathrm{C}$. Tissue culture treated flasks $\left(75 \mathrm{~cm}^{2}\right)$, centrifuge tubes $(50 \mathrm{ml})$ and cell culture dishes $(60$ $\mathrm{mm} \times 15 \mathrm{~mm}$ style) were obtained from Corning Incorporated (Corning, NY, USA).

Keratinocytes were sub-cultured using accutase $(70 \% \mathrm{v} / \mathrm{v}$ in DPBS). At 70-80\% confluence, cells were seeded into 96-well culture treated plates at a density of $35 \times 10^{3}$ cells/well, for further treatment and exposure to CS.

Exposure to CS. The keratinocyte SFM was exposed to CS in the smoking apparatus connected to a custom-made chamber (Figure 1). The device was adjusted to produce a combination of sidestream smoke $(89 \%)$ and mainstream smoke $(11 \%)$ as previously described (30). Briefly, CS was generated from ASSOS Papastratos brand cigarettes (ASSOS Papastratos, Xanthi, Greece; $10 \mathrm{mg}$ tar, $0.7 \mathrm{mg}$ nicotine, and $6 \mathrm{mg} \mathrm{CO}$ per cigarette). The above experiments were performed by following the standard Federal Trade Commission conditions (puff volume: $35 \mathrm{ml}$, puff duration: $3 \mathrm{~s}$, puff frequency: $1 / \mathrm{min}$ ). The keratinocyte SFM was exposed to the smoke of 8 cigarettes for $45 \mathrm{~min}$; the resulting medium was then diluted in a ratio 1:5 in order to be used on cells as CS-conditioned medium. Undiluted CS-conditioned medium was highly toxic, leading mouse keratinocytes immediately to necrosis; thus, the dilution 1:5 was selected as the lowest effective dose was used (based on data about keratinocyte viability and induced oxidative stress in relation to exposure time; data not shown).

Cell treatment. In order to assess the effects of CS on keratinocyte viability and oxidative stress, keratinocyte cells were incubated in CSconditioned media for $0.5 \mathrm{~h}, 1 \mathrm{~h}, 2 \mathrm{~h}$ and $3 \mathrm{~h}$. Furthermore, aiming to examine the potential protective effects of several compounds on keratinocytes, cells were pre-incubated for $24 \mathrm{~h}$ with keratinocyte SFM containing one of the following: i) nAchR inhibitors ( $\alpha$-bungarotoxin $0.1 \mu \mathrm{M}$ and hydrochloride mecamylamine $5 \mu \mathrm{M}$ ), ii) ascorbic acid $(250 \mu \mathrm{M})$ and rutin hydrate $(50 \mu \mathrm{M})$, iii) Pinus halepensis bark extract $(1 \mu \mathrm{g} / \mathrm{ml})$; this concentration was selected as the lowest effective dosage (data not shown) iv) nicotine $1 \mu \mathrm{M}, \mathrm{v}$ ) mixture of ascorbic acid $(250 \mu \mathrm{M})$ with rutin hydrate $(50 \mu \mathrm{M})$ and $\mathrm{nAchR}$ inhibitors $(\alpha-$ bungarotoxin $0.1 \mu \mathrm{M}$ and hydrochloride mecamylamine $5 \mu \mathrm{M}$ ), vi) Pinus halepensis bark extract $(1 \mu \mathrm{g} / \mathrm{ml})$ and $\mathrm{nAchR}$ inhibitors, vii) nicotine $1 \mu \mathrm{M}$ and $\mathrm{nAchR}$ inhibitors ( $\alpha$-bungarotoxin $0.1 \mu \mathrm{M}$ and hydrochloride mecamylamine $5 \mu \mathrm{M}$ ), viii) nicotine $1 \mu \mathrm{M}$ with ascorbic acid $(250 \mu \mathrm{M})$ and rutin hydrate $(50 \mu \mathrm{M})$, ix $)$ nicotine $1 \mu \mathrm{M}$ and Pinus halepensis bark extract $(1 \mu \mathrm{g} / \mathrm{ml}), \mathrm{x})$ nicotine $1 \mu \mathrm{M}$ with ascorbic acid $(250 \mu \mathrm{M})$, rutin hydrate $(50 \mu \mathrm{M})$ and $\mathrm{nAchR}$ inhibitors $(\alpha$ bungarotoxin $0.1 \mu \mathrm{M}$ and hydrochloride mecamylamine $5 \mu \mathrm{M}$ ), xi) nicotine $1 \mu \mathrm{M}$ with Pinus halepensis bark extract $(1 \mu \mathrm{g} / \mathrm{ml})$ and $\mathrm{nAchR}$ inhibitors ( $\alpha$-bungarotoxin $0.1 \mu \mathrm{M}$ and hydrochloride mecamylamine $5 \mu \mathrm{M})$. Then, each group was incubated with CS-conditioned media containing the respective compound, for an extra period of $24 \mathrm{~h}$. After $48 \mathrm{~h}$ of total incubation of keratinocytes the viability was estimated for each experimental condition by performing the MTT assay. Cells incubated with keratinocyte SFM served as control. 


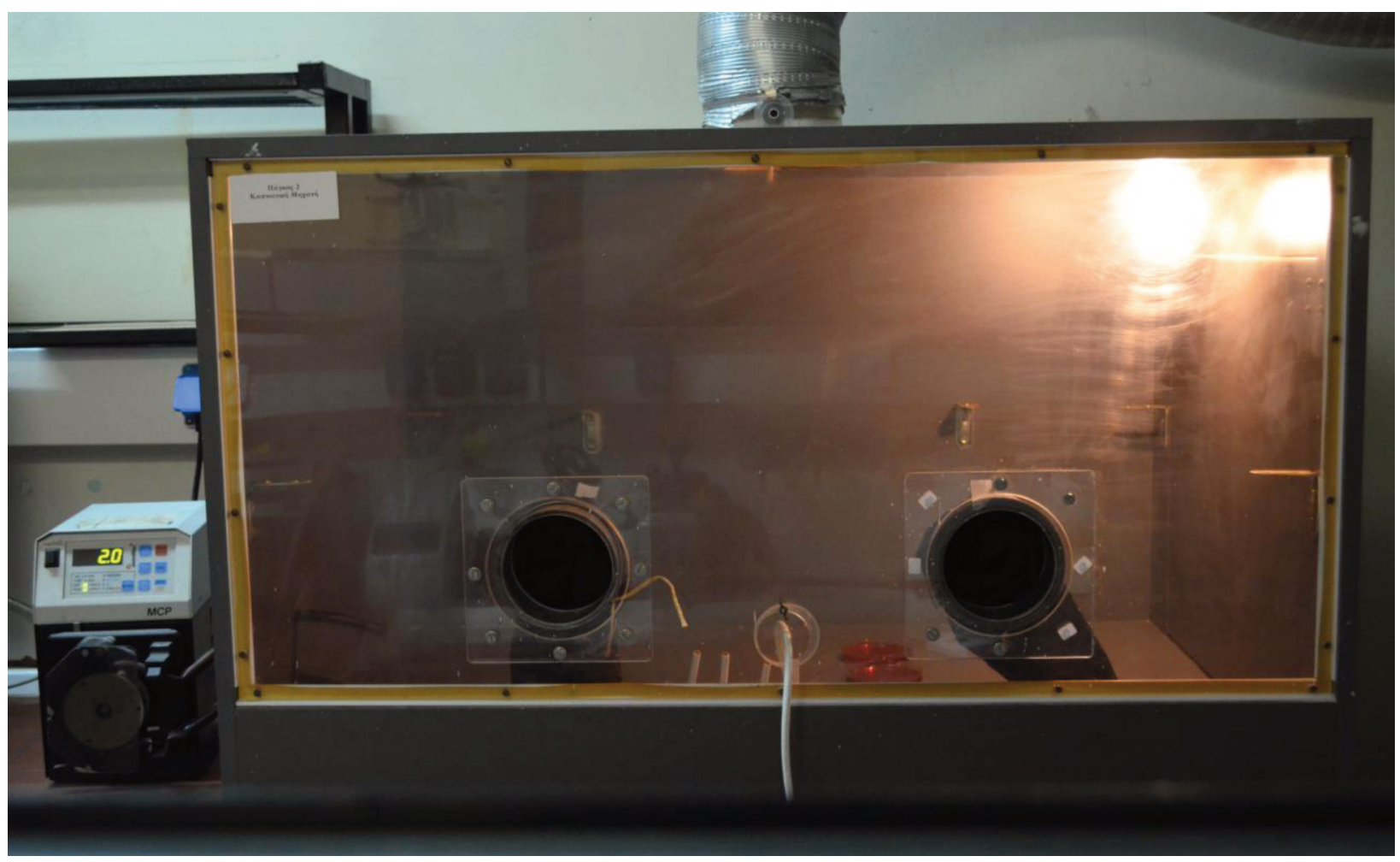

Figure 1. Plexiglass chamber connected to smoking device, which was used for the exposure of keratinocyte media to cigarette smoke.

Furthermore, keratinocyte cultures were incubated with CSconditioned media with or without Pinus halepensis bark extract (1 $\mu \mathrm{g} / \mathrm{ml}$ ), for $1 \mathrm{~h}, 2 \mathrm{~h}$ and $3 \mathrm{~h}$ in order to examine its effects on keratinocyte viability and oxidative stress.

Detection of reactive oxygen species (ROS) formation. Oxidative stress was evaluated on keratinocytes using chloro-methyl derivative of dichlorodihydrofluorescein (CM- $\left.\mathrm{H}_{2} \mathrm{DCFDA}\right)$. For this purpose, keratinocytes were cultured under the appropriate experimental condition (as mentioned above), in 96-well plates, for 4 and $24 \mathrm{~h}$. After the treatment, the cells were washed and $200 \mu \mathrm{l}$ of DPBS buffer was added in each well where $15 \mu$ of a fluorescent solution containing $0.083 \mathrm{~g} / 1 \mathrm{CM}-\mathrm{H}_{2} \mathrm{DCFDA}$ was added. The fluorescence of keratinocyte cells was monitored with the microplate reader using $485 \mathrm{~nm}$ excitation and $520 \mathrm{~nm}$ emission wavelengths. Fluorescence images obtained using a Canon PC1049, 16X (Tokyo, Japan) camera with Boligor (Tokyo, Japan) and Carl Zeiss 426126 and MC 80DX-1.0x (Oberkochen, Germany) for Axiovert 25 microscope Carl Zeiss (Oberkochen, Germany) adapters, with fluorescent light MBQ 52ac LEJ (Jena, Germany) emitter.

Cell viability assay. Cell viability was evaluated in keratinocytes after $48 \mathrm{~h}$ of CS-conditioned treatment using the MTT colorimetric assay. MTT diluted in DPBS was added to $100 \mu \mathrm{l}$ of keratinocyte SFM at a final concentration of $0.5 \mathrm{mg} / \mathrm{ml}$ in each well of $96-$ well plates. After $3 \mathrm{~h}$ of incubation $150 \mu \mathrm{l}$ of acidified isopropanol is added. The resulting absorbance of the formazan in each well was measured at $540 \mathrm{~nm}$ with the microplate reader.
Statistical analysis. The results were expressed as mean values \pm SD. All conditions (control and treated cells) were tested in five replications. Statistical differences were estimated using one-way analysis of variance (ANOVA with Bonferroni post-hoc test and were considered significant when $p<0.05$.

\section{Results}

Our experiments showed that exposure of keratinocytes to CS-conditioned medium for $2 \mathrm{~h}$ significantly decreased the viability $(p<0.001)$ and increased the oxidative stress $(p<0.05)$, reaching maximum values after $2 \mathrm{~h}$ of exposure. Keratinocyte viability was significantly decreased $(p<0.001)$ after $3 \mathrm{~h}$ of exposure to CS-conditioned medium (Figure 2). Exposure of keratinocytes in CS-conditioned medium for 4 $\mathrm{h}$ significantly increased the oxidative stress $(p<0.05)$, while further exposure, up to $24 \mathrm{~h}$, had no significant influence, most likely due to decrease of cell viability (Figure 3 ).

The protective effects of the antioxidants and/or nicotine and/or nAchR inhibitors on the viability of keratinocytes exposed to CS-conditioned medium are shown in Figure 4. According to the results, the presence of the antioxidants Lascorbic acid and rutin, as well as nAchR inhibitors did not show any protective effect against the impact CSconditioned medium on cell viability. On the contrary, Pinus 
a

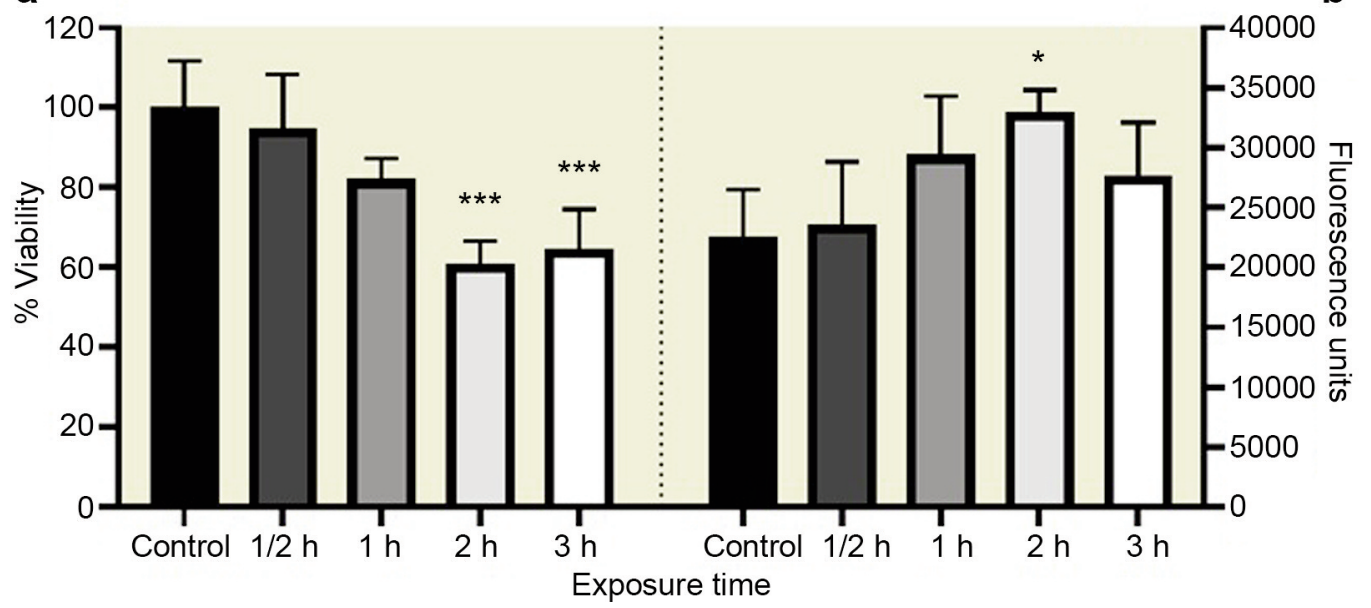

Figure 2. Kinetics of keratinocyte viability (a) and oxidative stress (b) after exposure to cigarette smoke-conditioned keratinocyte medium diluted 1:5. $* p<0.05 ; * * p<0.001$, compared to the control cells incubated with keratinocyte serum-free medium.

halepensis bark extract showed a significant protection of keratinocytes from CS-conditioned medium-induced damage, since it significantly increased their viability ( $p<0.05$, compared to cells treated only with CS-conditioned medium). Nicotine combined with Pinus halepensis bark extract in the presence or absence of $\mathrm{nAchR}$ inhibitors significantly protected keratinocytes from the CSconditioned medium-induced damage $(p<0.001$, compared to cells treated only with CS-conditioned medium). It is worth noting that this mixture of nicotine with Pinus halepensis bark extract enhanced keratinocyte viability even compared to non-exposed to CS-conditioned medium control cells $(p<0.01)$. It seems that nicotine could act synergistically even in the case of the non efficient by itself mixture of ascorbic acid, rutin and $\mathrm{nAchR}$ inhibitors $(p<0.05$; Figure 4).

The protective effect of Pinus halepensis bark extract on keratinocyte viability and oxidative stress after 1,2, and 3 $\mathrm{h}$ of exposure to CS-conditioned medium is presented in Figure 5. Pinus halepensis bark extract significantly protected the viability of keratinocytes; however, the data reached statistical significance only at $1 \mathrm{~h}$ of exposure $(p<0.001$; Figure 5a). It is clearly shown that incubation of keratinocytes with CS-conditioned media with Pinus halepensis extract for 1,2 , and $3 \mathrm{~h}$ significantly reduced oxidative stress $(p<0.001)$, even the endogenous one $(p<0.05)$, as this is expressed by the non treated control keratinocytes (Figure 5b). Fluorescence images confirmed the ability of Pinus halepensis bark extract to significantly reduce oxidative stress produced by CS-conditioned medium in different time points, included the endogenous one (Figure 6).

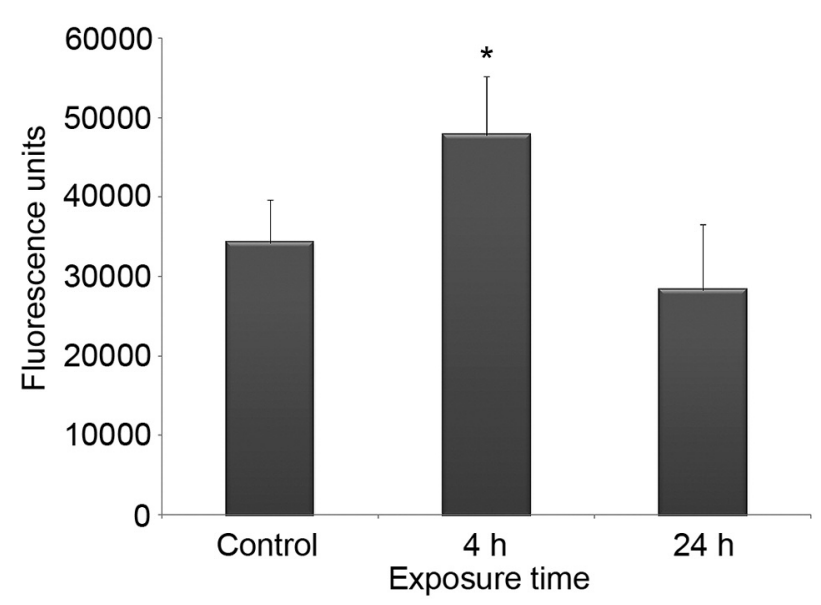

Figure 3. Oxidative stress in keratinocytes exposed to cigarette smokeconditioned keratinocyte medium, diluted 1:5, for $4 h$ and $24 h$. $*_{p}<0.05$, compared to the control cells incubated with keratinocyte serum-free medium.

\section{Discussion}

CS is well recognized as a strong oxidizing agent, producing substantial oxidative stress and inflammation mediators $(8$, 32). It exerts a strong carcinogenic effect (3), which is potentiated by UV radiation $(7,30,33)$. In the present study, epidermal cells (keratinocytes) exposed even in a diluted medium concentration of CS (1:5), had increased oxidative stress and decreased viability. Relevant results for the effect of CS have been previously observed by using similar assays on HaCat keratinocytes and oral keratinocytes co-cultured 


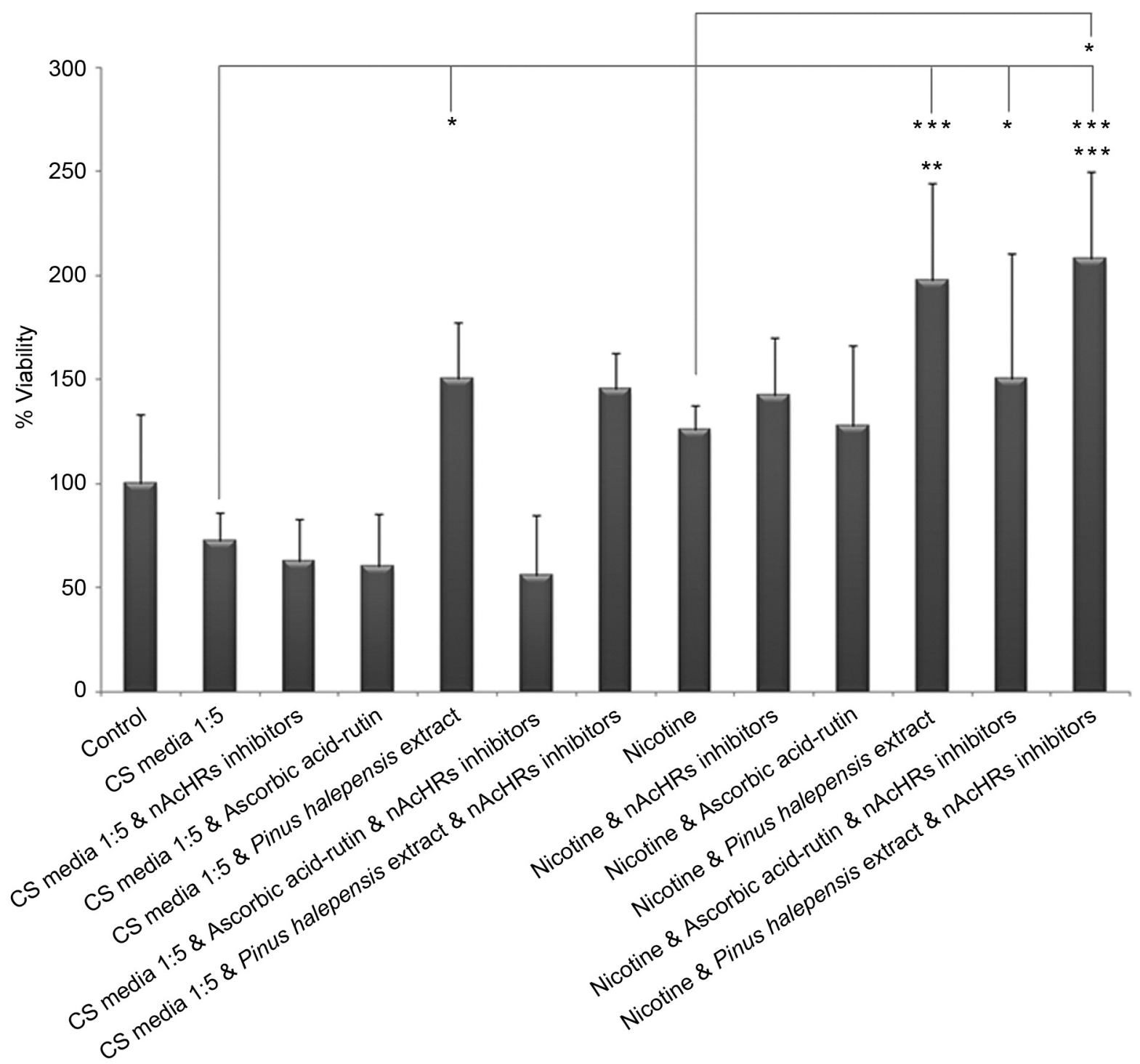

Figure 4. Keratinocyte viability (\%) in the presence of cigarette smoke conditioned keratinocyte medium diluted 1:5, nicotine, mixture of mecamylamine and $\alpha$-bungarotoxin (nAcHRs inhibitors), mixture of ascorbic acid and rutin, Pinus halepensis bark extract and their mixtures either with nicotine or mecamylamine and $\alpha$-bungarotoxin (nAcHRs Inhibitors). ${ }^{*} p<0.05 ; * * p<0.01 ;{ }^{* * *} p<0.001$ (compared to the CS-treated cells and the untreated control cells).

with fibroblast tissues (EpiOral or EpiGingival) (34-36). Particular efforts have been made to address the negative effects of CS either on reducing or even eliminating the oxidative stress. In this context, Pinus halepensis bark extract has been used, which showed significant antioxidant and anti-inflammatory properties upon tobacco smoke, UV or X-rays irradiation of mouse skin, in vivo (27-29, 37). Herein, our observations indicated that Pinus halepensis bark extract was able to protect primary mice keratinocytes from the effects of CS on both viability and oxidative stress, compared to other antioxidants or to the control (non treated) group. These results are in accordance with previous in vivo studies, which demonstrated that topical administration of Pinus halepensis protected the skin of hairless mice from the damage induced by CS and UV radiation $(27,37)$. It is noteworthy that the antioxidant mixture of ascorbic acid (250 $\mu \mathrm{M})$ with rutin $(50 \mu \mathrm{M})$, which was used as reference, did not show any protection on keratinocytes (Figure 4), although the same concentrations as those described in literature were used (38-40). Moreover, known antioxidants such as resveratrol, and a furaldehyde isolated from the extract of the Japanese apricot which decrease lipid 


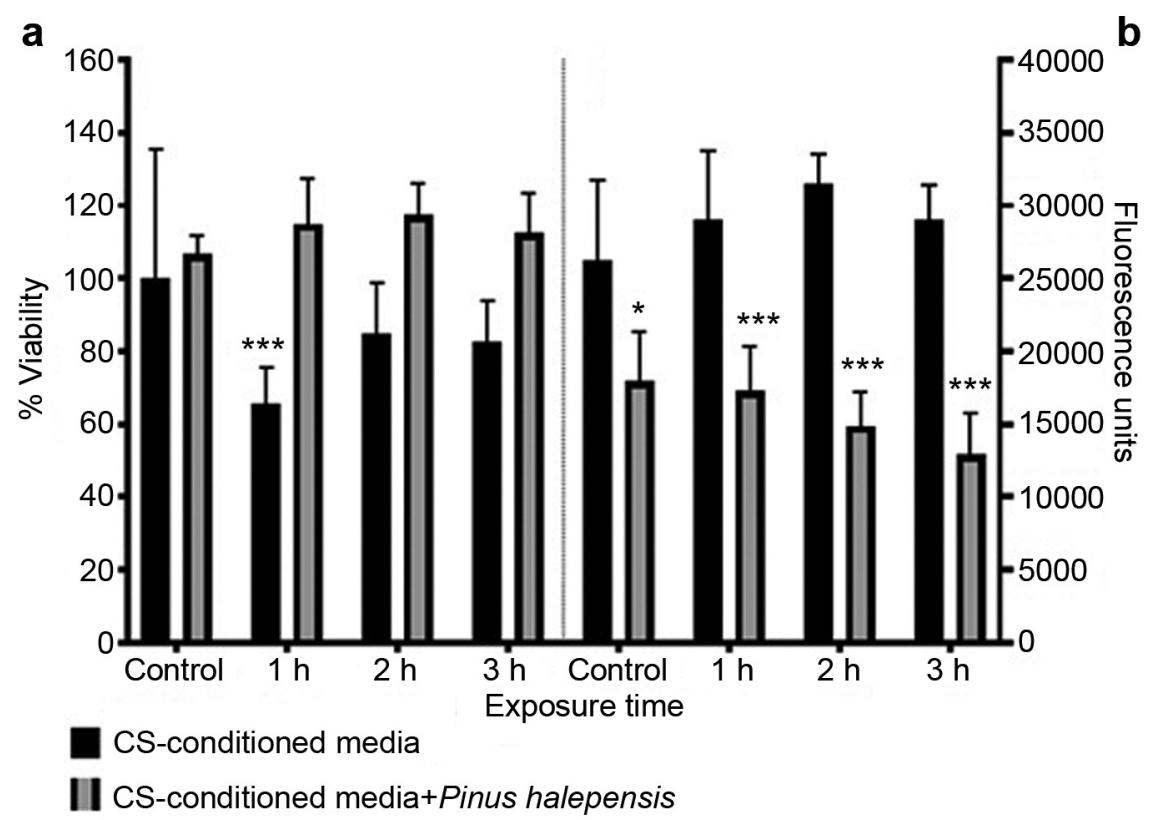

Figure 5. Protective effect of Pinus halepensis bark extract on the viability (a) and oxidative stress (b) of keratinocytes, exposed to cigarette smokeconditioned media for 1,2 , or $3 h . * p<0.05 ; * *<<0.01 ; * * p<0.001$ (compared to the cells treated only with CS-conditioned media, at each time point).
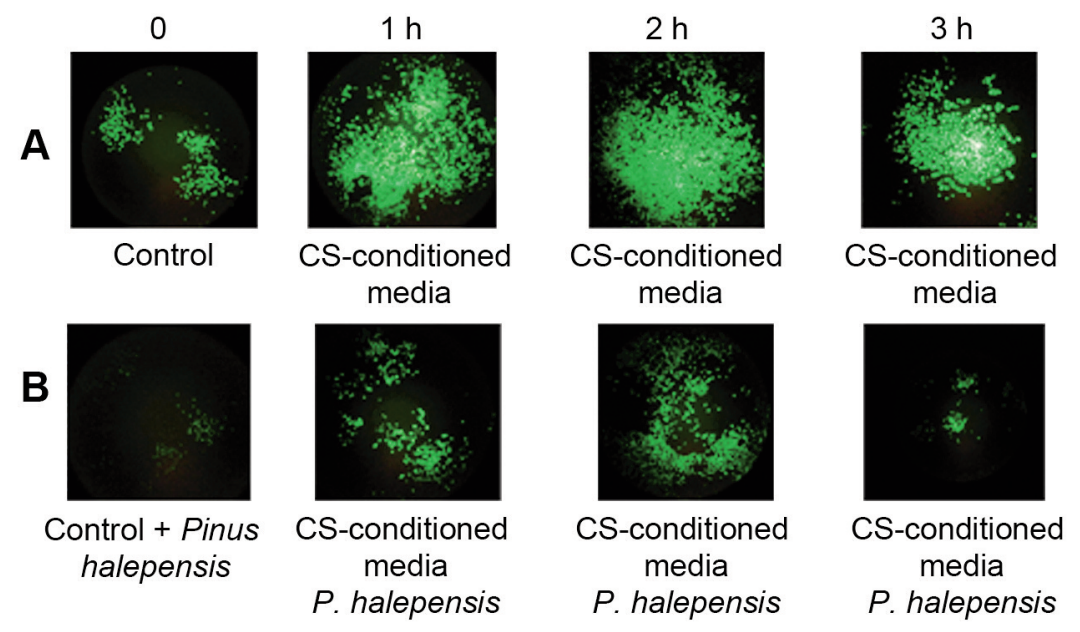

Figure 6. Fluorescence images of keratinocyte cultures before (0) and after exposure of 1, 2 and 3 h to CS-conditioned medium alone (A) or CSconditioned medium plus Pinus halepensis bark extract $(B)$. The green areas illustrate the oxidative stress induced by cigarette smoke.

peroxidation derived aldehydes and $N$-acetyl cysteine which attenuated the damage provided by CS have been shown to partially protect skin cells from the oxidative effects of CS $(36,41,42)$. However, the antioxidant-protective effect of Pinus halepensis bark extract seems to be even superior, since it is an agent able to absolutely inhibit oxidative stress or enhance viability even after the serious oxidative stress induced by CS-conditioned media (Figures 2-6).
Concerning the decisive answer on the in vitro effects of nicotine on skin, our data support its protective role on skin cells, especially when combined with antioxidants (Figure 4). This effect was enhanced when nicotine was combined with Pinus halepensis bark extract. It has been suggested that nicotine may act through the $\mathrm{nAChRs}$ by reducing the secretion of pro-inflammatory cytokines as TNF $\alpha$ and IL6 $(43,44)$. It has also been reported that nicotine has no 
antioxidant activity and in many cases has been used as an oxidizing agent creating reactive oxygen species in human endometrial cells or enhancing lipid peroxidation in brain and testis in vivo in rats $(45,46)$. However, in our experiment, the nAchR inhibitors did not show significant effects on keratinocytes (Figure 4). This could be due to either lower concentration or longer exposure $(24 \mathrm{~h})$ of keratinocytes to $\mathrm{nAchR}$ inhibitors, which were used in this study compared to the literature $(47,48)$.

In consistence with our results, other investigators have reported that nicotine inhibited the inflammation, thus minimizing the risk of atopic dermatitis, in vitro as well as in vivo, in keratinocytes and $\mathrm{BALB} / \mathrm{c}$ mice, respectively (43). Regarding the role of nicotine, the results are controversial, since there is data showing toxic effects of nicotine on oral keratinocytes or fibroblasts. One possible explanation for this inconsistency is that higher doses of nicotine were used in literature (44) compared to those in the present study.

The kinetic study on the effect of CS on control keratinocytes, showed an increase of oxidative stress and decrease of cell viability already in the first hours of exposure (Figures 2,3). The lowest effective dose of Pinus halepensis bark extract showed a significant protection against CS-induced oxidative stress, while it also decreased the endogenous ROS formation (Figure 5b). The results suggest that co-administration of Pinus halepensis bark extract with nicotine could be useful for in vivo preclinical studies, since this mixture is shown to exert enhanced protective effect against CS damage.

\section{Conclusion}

CS is highly harmful to keratinocytes, affecting both viability and oxidative stress. The negative effects of CS on viability and oxidative stress of keratinocytes were successfully inhibited by Pinus halepensis bark extract, while nicotine significantly enhanced their viability. The protective activity on keratinocytes was further enhanced when these two agents were used in combination, at wellestablished doses. The results seem promising for the use of Pinus halepensis bark extract to minimize the damaging effects of CS on skin.

\section{Conflicts of Interest}

The Authors have no conflicts of interest to declare.

\section{Authors' Contributions}

Pavlou P contributed to the realization of the study and writing of the manuscript. Antoniadou I, Peraki A, Vitsos A, Dallas P, and Papaioannou G contributed to the realization of this work. Mostratos D. worked on results, performed the statistical tests, and contributed to the figures. Deliconstantinos G, Grando SA, and Rallis M contributed to the conception writing and realization of the study.

\section{Acknowledgements}

The Authors would like to thank Professors Drs Konstantinos Vagias $^{\dagger}$, Vassilios Roussis and Efstathia Ioannou for their contribution to obtain Pinus halepensis bark extract and Mrs Styliani Tounta for her assistance on figures presentation.

\section{References}

1 Environmental Health 2019: Tobacco May 29, 2019, World Health Organization (WHO) Available at: http://www.who.int/newsroom/fact-sheets/detail/tobacco (Accessed on June 2019)

2 Landrigan PJ, Fuller R, Acosta NJR, Adeyi O, Arnold R, Basu N, Baldé AB, Bertollini R, Bose-O'Reilly S, Boufford JI, Breysse PN, Chiles T, Mahidol C, Awa M Coll-Seck, Cropper ML, Fobil J, Fuster V, Greenstone M, Haines A, Hanrahan D, Hunter D, Khare M, Krupnick A, Lanphear A, Lohani B, Martin K, Mathiasen KV, McTeer MA, Murray CJL, Ndahimananjara JD, Perera F, Potočnik J, Preker AS, Ramesh J, Rockström J, Salinas C, Samson LD, Sandilya K, Sly PD, Smith KR, Steiner A, Stewart RB, Suk WA, van Schayck OCP, Yadama GN, Yumkella $\mathrm{K}$ and Zhong KWM: The Lancet Commission on pollution and health, The Lancet Commissions. Lancet 391: $462-$ 512, 2018. PMID: 29056410. DOI: 10.1016/ S01406736(17)32345-0

3 Hussain A, Dulay P, Rivera M N, Aramouni C and Saxena V: Pathogenesis associated with cigarette carcinogens. Neoplastic Cureus 11(1): e3955, 2019. PMID: 30956908. DOI: 10.7759 /cureus. 3955

4 DiGiacomo SI, Jazayeri MA, Barua RS and Ambrose JA: Environmental tobacco smoke and cardiovascular disease. Int J Environ Res Public Health 96(16): 1-12, 2019. PMID: 30602668. DOI: 10.3390/ijerph16010096

5 Ahn K: The role of air pollutants in atopic dermatitis. J. Allergy Clin Immunol 134: 993-999, 2014. PMID: 25439225. DOI: 10.1016/j.jaci2014.09.02

6 Bontamonte D, Vestita M, Filoni A, Mastrolonardo M, Angelini $\mathrm{M}$ and Foti C: Tobacco-induced contact dermatitis. Eur J Dermatol 26(3): 223-231, 2016. PMID: 2702049. DOI: 10.1684/ejd.2016.2771

7 Dusingize JC, Olsen CM, Pandeya NP, Subramaniam P, Thompson BS, Neale RE, Green AC and Whiteman DC: Cigarette smoking and the risks of basal cell carcinoma and squamous cell carcinoma. J Invest Dermatol 37: 1700-1708, 2017. PMID: 28414022. DOI: 10.1016/j.jid.2017.03.027

8 Pecorelli A, Woodby B, Prieux R and Valacchi G: Involvement of 4-hydroxy-2-nonenal in pollution-induced skin damage. Biofactors 45(4): 536-547, 2019. PMID: 31087730. DOI: 10.1002/biof.1513

9 Lourenco MAM, Braz MG, Aun AG, Pereira BLB, Fernandes FH, Kazmarek EM, Bachiega TF, Garcia Zanati SG, Azevedo PS, Polegato BF, Fernandes AAH,Rupp de Paiva SA, Zornoff LAM and Minicucci MF: Lipid damage is the best marker of oxidative injury during the cardiac remodeling process induced by tobacco smoke. BMC Pharmacol Toxicol 19(74): 1-7, 2018. PMID: 30446004. DOI: 10.1186/s40360-018-0268-4 
10 Alsaad AM, Al-Arifi MN, Maayah ZH, Attafi IM, Alanazi FE, Belali OM, Alhoshani A, Asiri YA and Korashy HM: Genotoxic impact of long-term cigarette and waterpipe smoking on DNA damage and oxidative stress in healthy subjects. Toxicol Mech Methods 29(2): 119-127, 2019. DOI: 10.1080/15376516.2018.1528650

11 Colombo G, Garavaglia Ml, Astori E, Giustarini D, Rossi R, Milzani A and Dalle-Donne I: Protein carbonylation in human bronchial epithelial cells exposed to cigarette smoke extract. Cell Biol Toxicol 35: 345-360, 2019. PMID: 30648195. DOI 10.1007/s10565-019-09460-0

12 Boukhenouna S, Wilson MA, Bahmed K and Kosmider B: Reactive oxygen species in chronic obstructive pulmonary disease. Oxid Med Cell Longev 2018: 5730395, 2018. PMID: 29599897. DOI: $10.1155 / 2018 / 5730395$

13 Strzelak A, Ratajczak A, Adamiec A and FeleskoW: Tobacco smoke induces and alters immune responses in the lung triggering inflammation, allergy, asthma and other lung diseases: A mechanistic review. Int J Environ Res Public Health 15(5): pii: E1033, 2018. PMID: 29883409. DOI: 10.3390/ijerph15051033

14 Zirak MR, Mehri S, Karimani A, Zeinali M, Hayes AW and Karimi G: Mechanisms behind the atherothrombotic effects of acrolein, a review. Food Chem Toxicol 129: 38-53, 2019. PMID: 31009736. DOI: 10.1016/j.fct.2019.04.034

15 Arredondo J, Nguyen VT, Chernyavsky AI, Jolkovsky DL, Pinkerton KE and Grando SA: A receptor-mediated mechanism of nicotine toxicity in oral keratinocytes. Lab Invest 81(12): 1653-1668, 2001. PMID: 11742036. DOI: 10.1038/labinvest.3780379

16 Kabbani N and Nichols RA: Beyond the channel: metabotropic signaling by nicotinic receptors. Trends Pharmacol Sci 39(4): 354366, 2018. PMID: 29428175. DOI: 10.1016/j.tips.2018.01.002

17 Bertrand D and Terry Jr AV: The wonderland of neuronal nicotinic acetylcholine receptors. Biochem Pharmacol 151: 214225, 2018. PMID: 29248596. DOI 10.1016/j.bcp.2017.12.008

18 Quik M: Smoking, nicotine and Parkinson's disease. Trends Neurosci 27(9): 561-568, 2004. PMID: 15331239. DOI: 10.1016/j.fct.2019.04.034

19 Alotaibi F, Abounasef SK and Fikry H: Effects of combined nicotine and caffeine on the rat skeletal muscles: A histological and immunohistochemical study. J Microsc Ultrastruct 7(4): 14712, 2019. PMID: 31803568. DOI: 10.4103/JMAU.JMAU_1_19

20 Zhang Q, Ganapathy S, Avraham H, Nishioka T and Chen C: Nicotine exposure potentiates lung tumorigenesis by perturbing cellular surveillance. Br J Cancer, 2020. PMID: 32001831 DOI: 10.1038/s41416-020-0730-0

21 Gao Q, Bi P, Luo D, Guan Y, Zeng W, Xiang H, Mi Q, Yang G, Li $\mathrm{X}$ and Yang B: Nicotine-induced autophagy via AMPK/mTOR pathway exerts protective effect in colitis mouse model. Chem Biol Interact 317: 108943, 2020. PMID: 31926917. DOI: 10.1016/j.cbi.2020.108943

22 Malińska D, Więckowski MR, Michalska B, Drabik K, Prill M,Patalas-Krawczyk P, Walczak J, Szymański J, Mathis C, Van der Toorn M, Luettich K, Hoeng J, Peitsch MC, Duszyński J and Szczepanowska J: Mitochondria as a possible target for nicotine action. J Bioenerg Biomembr 51(4): 259-276, 2019. PMID: 31197632. DOI: $10.1007 / \mathrm{s} 10863-019-09800-\mathrm{Z}$

23 Kishibe M, Griffin TM, Radek KA: Keratinocyte nicotinic acetylcholine receptor activation modulates early TLR2-mediated wound healing responses. Int Immunopharmacol 29(1): 63-70, 2015. PMID: 26071220. DOI: 10.1016/j.intimp.2015.05.047
24 Xanthoulea S, Deliaert A, Romano A, Rensen SS, Buurman WA and van der Hulst RR: Nicotine effect on inflammatory and growth factor responses in murine cutaneous wound healing. Int Immunopharmacol 17(4): 1155-1164, 2013. PMID: 24201082. DOI: $10.1016 /$ j.intimp.2013.10.022

25 Burke KE: Mechanisms of aging and development-A new understanding of environmental damage to the skin and prevention with topical antioxidants. Mech Ageing Dev 172: 123130, 2018. PMID: 29287765. DOI: 10.3892/ijmm.2018.4025

26 Choi KS, Kundu JK, Chun KS, Na HK and Surh YJ: Rutin inhibits UVB radiation-induced expression of COX-2 and iNOS in hairless mouse skin: p38 MAP kinase and JNK as potential targets. Arch Biochem Biophys 59: 38-45, 2014. PMID: 24875145. DOI: 10.1016/j.abb.2014.05.016

27 Dimaki A, Kyriazi M, Leonis G, Sfiniadakis I, Papaioannou GT, Ioannou E, Roussis V and Rallis M: Diabetic skin and UV light: Protection by antioxidants. Eur J Pharm Sci 127: 1-8, 2019. PMID: 30316976. DOI: 10.1016/j.ejps.2018.10.010

28 Meimeti E, Kafanas A, Pavlou P, Evangelatou A, Tsouparelou P, Kanellopoulos S, Kipouros P, Koliarakis N, Leonis G, Ioannou E, Roussis V and Rallis M: Topical treatment of skin injury inflicted in mice by X-ray irradiation. Skin Pharmacol Physiol 31(4): 175183, 2018. PMID: 29617695. DOI: 10.1159/000487404

29 Petri A, Alexandratou E, Kyriazi M, Rallis M, Roussis V and Yova D: Combination of Fospeg-IPDT and a natural antioxidant compound prevents photosensitivity in a murine prostate cancer tumour model. Photodiagnosis Photodyn Ther 9(2): 100-108, 2012. PMID: 22594979. DOI: 10.1016/j.pdpdt.2011.11.002

30 Pavlou P, Rallis M, Deliconstantinos G, Papaioannou G and Grando SA: In-vivo data on the influence of tobacco smoke and UV light on murine skin. Toxicol Ind Health 25(4-5): 231-239, 2009. PMID: 19651792 . DOI: 10.1177/0748233709103209

31 Kyriazi M, Yova D, Rallis M and Lima A: Cancer chemopreventive effects of Pinus maritima bark extract on ultraviolet radiation and ultraviolet radiation-7,12, dimethylbenz(a)anthracene induced skin carcinogenesis of hairless mice. Cancer Lett 237(2): 234-241, 2006. PMID: 16019129. DOI: 10.1016/j.canlet.2005.06.005

32 Gutowska K, Formanowicz D and Formanowicz P: Selected aspects of tobacco-induced prothrombotic state, inflammation and oxidative stress: Modeled and analyzed using petri nets. Interdiscip Sci 11(3): 373-386, 2019. PMID: 30584644. DOI: 10.1007/s12539-018-0310-7

33 Marrot L: Pollution and sun exposure: A deleterious synergy. Mechanisms and opportunities for skin protection. Curr Med Chem 25(40): 5469-5486, 2018. PMID: 2892587. DOI: 10.2174/0929867324666170918123907

34 Avezov K, Reznick AZ and Aizenbud D: Time and dose effects of cigarette smoke and acrolein on protein carbonyl formation in HaCaT keratinocytes. Adv Exp Med Biol 849: 57-64, 2014. PMID: 25398315. DOI: 10.1007/5584_2014_91

35 Schlage WK, Iskandar AR, Kostadinova R, Xiang Y, Sewer A, Majeed S, Kuehn D, Frentzel S, Talikka M, Geertz M, Mathis C, Ivanov $\mathrm{N}$, Hoeng $\mathrm{J}$ and Peitsch MC: In vitro systems toxicology approach to investigate the effects of repeated cigarette smoke exposure on human buccal and gingival organotypic epithelial tissue cultures. Toxicol Mech Methods 24(7): 470-487, 2014. PMID: 25046638. DOI: 10.3109/15376516.2014.943441

36 Avezov K, Reznick AZ and Aizenbud D: Oxidative damage in keratinocytes exposed to cigarette smoke and aldehydes. Toxicol 
In Vitro 28(4): 485-491, 2014. PMID: 24444448. DOI: 10.1016/j.tiv.2014.01.004

37 Zoumpliou V, Stamatiadi M, Vassiliadis C, Rallis M, Papaioannou GT, Liakos S, Angelou A, Daskalaki S, Kyriazi M, Roussis V and Vagias C: Effect of cigarette smoke on diabetic skin and protection with topical administration of Pinus halepensis extract. Am J Plant Sci 5(26): 3964-3973, 2014. DOI: 10.4236/ajps.2014.526415

38 Hanada Y, Iomori A, Ishii R, Gohda E and Tai A: Protection of free radical-induced cytotoxicity by $2-\mathrm{O}-\alpha-\mathrm{d}$-glucopyranosyl-1ascorbic acid in human dermal fibroblasts. Biosci Biotechnol Biochem 78(2): 301-306, 2014. PMID: 25036685. DOI: 10.1080/09168451.2014.882756

39 Shima N1, Kimoto M, Yamaguchi M and Yamagami S: Increased proliferation and replicative lifespan of isolated human corneal endothelial cells with L-ascorbic acid 2-phosphate. Invest Ophthalmol Vis Sci 52(12): 8711-8717, 2011. PMID: 21980003. DOI: 10.1167/iovs.11-7592

40 Wang W, Wu QH, Sui Y, Wang Y and Qiu X: Rutin protects endothelial dysfunction by disturbing Nox4 and ROS-sensitive NLRP3 inflammasome. Biomed Pharmacother 86: 32-40, 2017. PMID: 27936392. DOI: 10.1016/j.biopha.2016.11.134

41 Jang AJ, Lee JH, Yotsu-Yamashita M, Park J, Kye S, Benza RL, Passineau MJ, Jeon YJ and Nyunoya T: A novel compound, "FA-1" isolated from Prunus mume, protects human bronchial epithelial cells and keratinocytes from cigarette smoke extractinduced damage. Sci Rep 8(1): 11504, 2018. PMID: 30065307. DOI: $10.1038 / \mathrm{s} 41598-018-29701-2$

42 Sticozzi C, Cervellati F, Muresan XM, Cervellati C and Valacchi G: Resveratrol prevents cigarette smoke-induced keratinocytes damage. Food Funct 5(9): 2348-2356, 2014. PMID: 25088477. DOI: $10.1039 / \mathrm{c} 4$ fo00407h
43 Garg BK and Loring RH: GTS-21 has cell-specific antiinflammatory effects independent of $\alpha 7$ nicotinic acetylcholine receptors. PLoS ONE 14(4): e0214942, 2019. PMID: 30947238. DOI: 10.1371/journal.pone.0214942

44 Roman S, Badia A, Camps P and Clos MV: Potentiation effects of $(+/$-)huprine $\mathrm{X}$, a new acetylcholinesterase inhibitor, on nicotinic receptors in rat cortical synaptosomes. Neuropharmacology 46: 95-102, 2004. PMID: 14654101. DOI: 10.1016/j.neuropharm.2003.08.005

45 Saad AB, Rjeibi I, Brahmi N, Elaloui E and Zouari N: Nicotineinduced oxidative stress, testis injury, $\mathrm{AChE}$ inhibition and brain damage alleviated by Mentha spicata. Inflammopharmacology, 2019. PMID: 31646410. DOI: 10.1007/s 10787-019-00650-0

46 Khademi F, Totonchi H, Mohammadi N and Zare R: Nicotineinduced oxidative stress in human primary endometrial cells. Int J Toxicol 38(3): 202-208, 2019. PMID: 31113282. DOI: $10.1177 / 1091581819848081$

47 Dong J, Segawa R, Mizuno N, Hiratsuka M and Hirasawa N: Inhibitory effects of nicotine derived from cigarette smoke on thymic stromal lymphopoietin production in epidermal keratinocytes. Cell Immunol 302: 19-25, 2016. PMID: 26786889. DOI: 10.1016/j.cellimm.2016.01.001

48 Desjardins J and Grenier D: Neutralizing effect of green tea epigallocatechin-3-gallate on nicotine-induced toxicity and chemokine (C-C motif) ligand 5 secretion in human oral epithelial cells and fibroblasts. J Investig Clin Dent 3(3): 189-197, 2012. PMID: 22887905. DOI: 10.1111/j.2041-1626.2011.00103.x

Received August 21, 2019

Revised April 21, 2020

Accepted April 29, 2020 